\title{
OPTICAL STARK EFFECT IN ORIENTED PSEUDOISOCYANINE J-AGGREGATES
}

\author{
R. Gadonas, A. Čiburys, and A. Savickas \\ Department of Quantum Electronics and Laser Research Centre, Vilnius University, Sauletekio 9, LT-10222 Vilnius, Lithuania \\ E-mail: roaldas.gadonas@ff.vu.lt
}

Received 5 March 2007

\begin{abstract}
The optical Stark effect (OSE) has been studied in highly oriented J-aggregates of 1,1'-diethyl-2,2'-cyanine chloride (PIC$\mathrm{Cl}$ ) in vertically spin-coated PVA film under far off-resonance pump by $1 \mathrm{ps}$ pulses at $1055 \mathrm{~nm}$. Blue shift of few tens of $\mathrm{cm}^{-1}$, bleaching, and broadening of the J-band were observed. The induced changes in absorption showed instantaneous character of OSE. Polarization dependence observed is qualitatively explained supposing the dual nature of the J-band. Observed Stark shift of nearly the same magnitude in dye monomer solution indicates no exciton enhancement of the aggregate OSE response induced by far off-resonance light pulses.
\end{abstract}

Keywords: J-aggregates, optical Stark effect, OSE

PACS: $42.50 . \mathrm{Hz}, 78.67 .-\mathrm{n}$

\section{Introduction}

The fast control of optical properties of the organic molecular systems with quantum confinement effects by non-resonant light pulses has become a subject of active study. The potentials of J-aggregates to be used as elements for all optical computing are due to size enhancement of absorption transitions and third order nonlinear susceptibilities as a result of cooperative response of 1D-confined Frenkel excitons to the light field.

The exciton size effect on nonlinear optical properties of J-aggregates was examined for the first time by theoretical work of Spano and Mukamel [1]. The near resonance third order nonlinear optical susceptibility was predicted to be scaled as square of the optical (coherent) aggregate size $N[1,2]$ in the case of fast dephasing. For far off-resonance case, the nonlinear third rank susceptibility was predicted to be linearly dependent on $N$. The optical Stark effect was theoretically treated by Mukamel et al [3]. Transients under virtual excitation by slightly off-resonant femtosecond pulses were reported by Sasaki et al $[4,5]$ in pseudoisocyanine bromide at low temperatures. However, the case of non-resonant pump still remains poorly examined experimentally.

In this paper, we report the results of the study of optical Stark effect (OSE) in J-aggregates of 1,1'- diethyl-2,2'-cyanine chloride (pseudoisocyanine chloride) at room temperature under the conditions of far off-resonance pump. The exciton dephasing time was short compared to the duration of pump and probe pulses.

\section{Materials and methods}

The samples studied were vertically spin-coated films of 1,1'-diethyl-2,2'-cyanine chloride (PIC) J-aggregates in polyvinyl alcohol (PVA) (for preparation details see [6]). For preparing highly oriented J-aggregates by this technique, primarily $80 \mathrm{mg}$ PVA was dissolved in distilled water at $\sim 95^{\circ} \mathrm{C}$. Then $8 \mathrm{mg}$ of PIC (Filmfabrik Wolfen GmbH, without further purification) was added into the hot solution. The substrate - a rectangular glass plate - was attached to the shaft of an electric motor with the shorter edge of substrate parallel to the shaft. The solution was placed on the plate before spinning, and it spread over along the substrate surface in the radial direction by rotation. Spinning speed of substrate was about $2000 \mathrm{rpm}$. The J-aggregate absorption band had a maximum at $572 \mathrm{~nm}$ and a bandwidth of $275 \mathrm{~cm}^{-1}$ at the polarization parallel to orientation direction (the long rectangle axis) of the film (Fig. 1). The absorption spectra had been recorded using fibre optic spectrometer AvaSpec- 


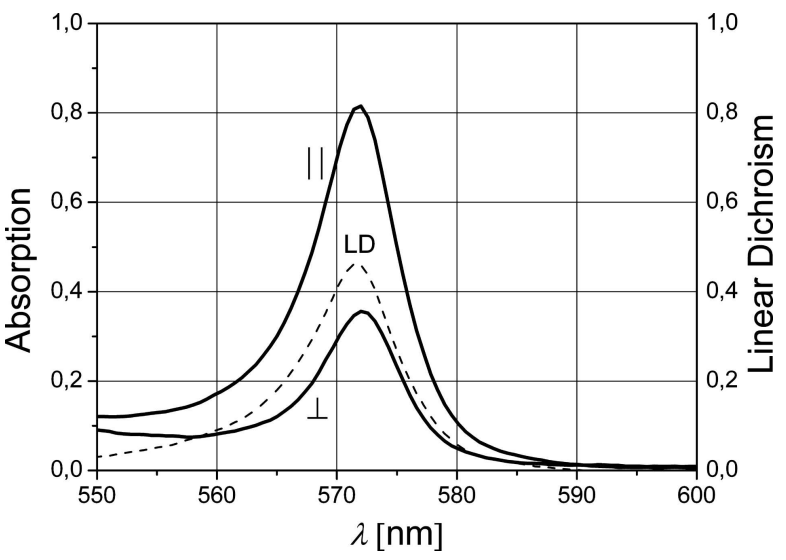

Fig. 1. Absorption and linear dichroism spectra of PIC/PVA film. Symbol $\|$ marks absorption for polarization parallel to orientation direction, $\perp$ is for perpendicular polarization, $L D$ is for linear dichroism.

2048TEC-2 (Avantes BV) additionally placing a thin film polarizer at entrance to spectrometer's fibre.

The pump-probe experiments were carried out using mode-locked $\mathrm{Nd}$ : glass laser and optical parametrical amplifier (OPA) (Light Conversion Ltd.). The fundamental frequency of the laser $(1055 \mathrm{~nm})$ was used to induce the off-resonance OSE in J-aggregates at the detuning from resonance (J-band) of about $8000 \mathrm{~cm}^{-1}$. The Gaussian beam diameter on the sample was $0.72 \mathrm{~mm}$ at $1 / \mathrm{e}^{2}$ of the maximal intensity. The FWHM of the pump pulse was 1.3 ps as determined by the second harmonic generation (SHG) autocorrelation technique; the intensity profile was well fitted by $\operatorname{sech}^{2}(t)$. The energy of the pump pulse was varied from 25 up to $150 \mu \mathrm{J}\left(7.5-45 \mathrm{GW} \mathrm{cm}^{-2}\right.$ intensity range). The second harmonic $(527.5 \mathrm{~nm})$ has been used in experiments with resonance pump. Polarization of the pump beam was changed by using half-wave plate. The pump induced absorption changes around the J-band were scanned by tunable probe (second harmonics of OPA). All the experiments were performed at room temperature. Further in this article the orientations of polarizations of pump and probe beams are referred to with respect to orientation direction of the film.

\section{Results and discussion}

Figure 1 shows the absorption spectra of aggregates in the film at parallel and perpendicular polarizations of the light with respect to the orientation direction. Linear dichroism $L D=A^{\|}-A^{\perp}$ and absorption spectra reveal that part of aggregates have been oriented by shear force during the spinning so that their dipole transitions become parallel to the direction of centrifugal force. However, the anisotropy reached shows that there is a part of aggregates which are less affected by coating process and are distributed more isotropically. The latter observation is well consistent with the assumption of Kobayashi et al [7,8] about the existence of two kinds of species in the coated film: macroaggregates and mesoaggregates. Although the shape of the band is similar for both polarizations (Fig. 1), the absorption band for perpendicular polarization is slightly red-shifted compared to that for parallel one. As a result, maximum of dichroism is observed at $571.5 \mathrm{~nm}$, which is "blue" fraction of absorption band. Thus, we observe clear evidence of inhomogeneous nature of the J-band as "blue" and "red" fractions differently respond to aligning force. Similar conclusions have been drawn by Misawa et al [9] from spectral hole burning experiments as well as from electroabsorption [10].

Different polarizations of both pump and probe beams were used in measurement of transient absorption spectra. As seen from Fig. 2 (middle), in all cases the off-resonant pump-induced changes in absorption have dispersion-like shape with zero at $\sim 571 \mathrm{~nm}$, which is close to wavelength of the peak of J-band. The shape of the spectra are similar to what is attributed to real excitons created by the absorption of resonant pump (Fig. 2, top) but there are few major differences between resonant and off-resonant pump. The first difference is the contribution of stimulated emission in the resonant pump case which is not present at nonresonance pump. Moreover, in the latter case a small induced transient absorption is present at long wavelength side $(>580 \mathrm{~nm})$. The second difference is different response to polarization of the pump. In the case of resonant pump the changes of absorption measured with parallel polarization of the probe were bigger for perpendicular polarization of the pump (Fig. 2, top). In the case of off-resonant pump the biggest absorption changes were detected in the case when both probe and pump polarizations were parallel to orientation direction (Fig. 2, middle). Third, the time behaviour of off-resonant pump-induced changes show instantaneous character, the change in optical density exactly following the intensity variation in the $\operatorname{sech}^{2}(t)$ pulse with 1.3 ps duration (Fig. 3). In contrast, real excitons created by resonance pump result in slowly decaying absorption changes with characteristic decay time of $(20 \pm 4)$ ps. Signatures of real excitons created due to two-photon absorption (TPA) appear also in the case of non-resonance pump as small residuals observed at longer delays of the probe pulse, as seen from Fig. 3, 


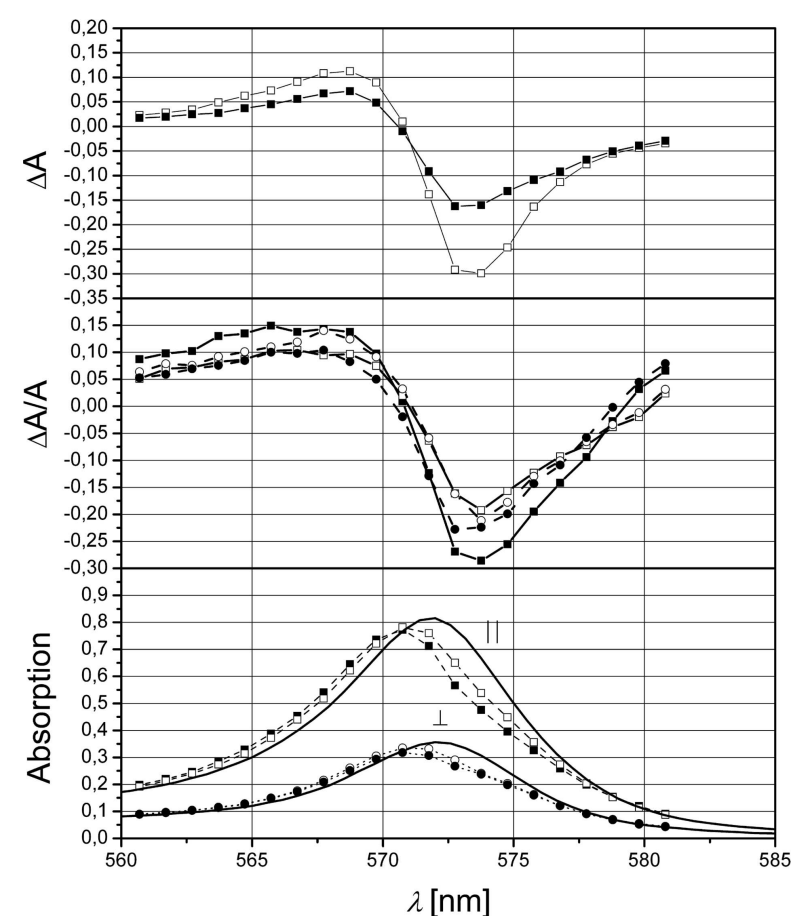

Fig. 2. Top, spectra of zero delay differential absorption for resonance pump (527 nm, $\left.37 \mathrm{MW} \mathrm{cm}^{-2}\right)$ : parallel pump - parallel probe, $(\|\|), \mathbf{\square} ;(\perp \|), \square$. Middle, zero delay differential absorption normalized to steady state absorption for off-resonance pump (1055 nm, $\left.22.6 \mathrm{GW} \mathrm{cm}^{-2}\right)$ : (\| \|), $\mathbf{\square} ;(\perp \|), \square ;(\| \perp), \circ$; $(\perp \perp)$, •. Bottom, absorption of non-affected (solid lines) and OSE affected samples measured at zero delay. Symbols and lines for different polarizations the same as in the middle graph.

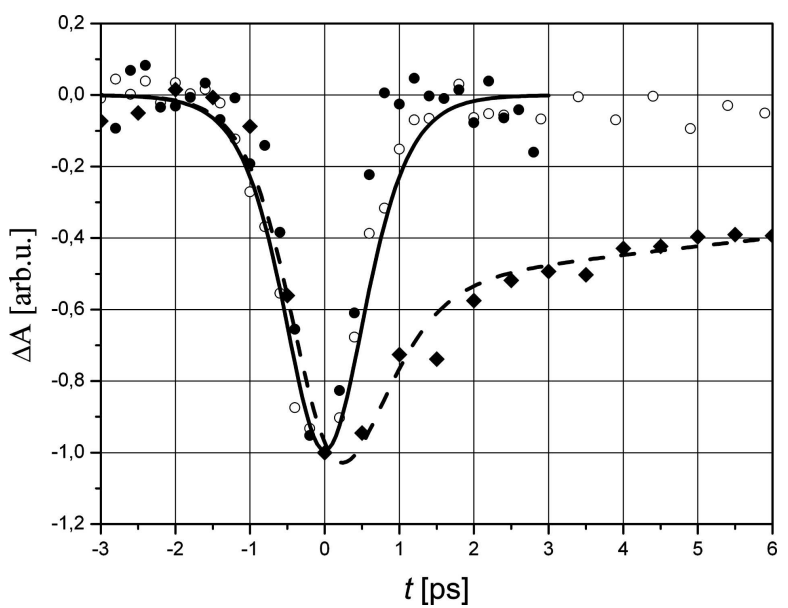

Fig. 3. Time dependences of normalized absorption changes: offresonance $(1055 \mathrm{~nm})$ pumped aggregates at $572 \mathrm{~nm}(\mathrm{o})$, monomers at $540 \mathrm{~nm}(\bullet)$, and resonance $(527 \mathrm{~nm})$ pumped aggregates at $572 \mathrm{~nm}(\mathbf{)})$. Dotted line is a convolution of pump pulse with twoexponential (exciton annihilation influenced) decay with time constants of 0.5 and $18 \mathrm{ps}$. Solid line is an intensity profile of $\mathrm{sech}^{2}$ pulse of 1.3 ps duration.

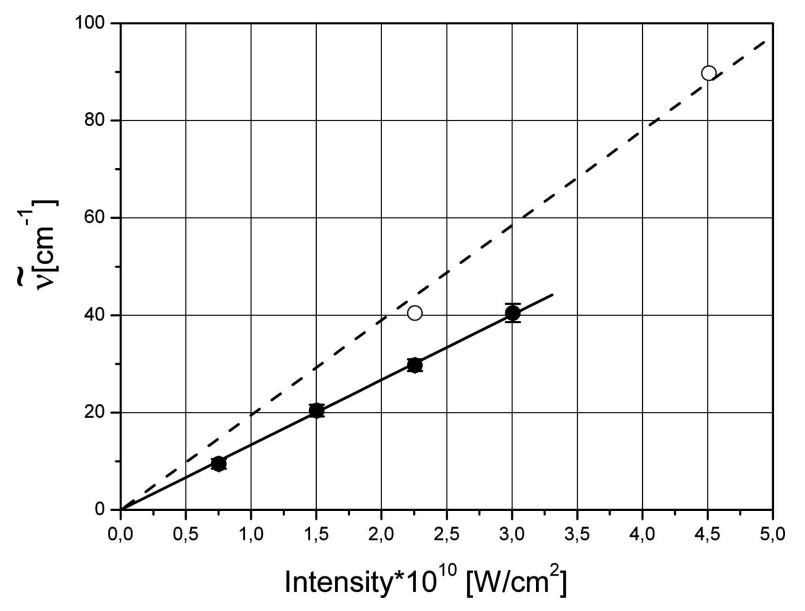

Fig. 4. Pump intensity dependences of the blue shift of aggregate (ם) and monomer (o) bands. Linear fits performed assuming zero OSE shift at zero pump intensity.

and are small enough (less than 5\%). Thus, the measured changes of absorption are associated mainly with far off-resonance OSE.

Figure 2 (bottom) shows OSE affected absorption band for different cases calculated from measured steady state and differential absorption spectra. In order to estimate the shift of the maximum of the J-band, the OSE affected absorption band (we took 11-12 points around the peak) was fitted by Gaussian function. The same procedure has been applied for the steady state spectrum. The main feature observed in all cases is the OSE induced blue shift of the J-band which is proportional to the intensity of the pump (Fig. 4). To estimate the shift for monomers, the $10^{-4} \mathrm{M}$ methanol solution of the dye was prepared. To measure the shift, the $540 \mathrm{~nm}$ probe wavelength has been chosen which corresponds to the maximum slope of monomer absorption band. The calculated blue shift at zero delay of probe pulse $\Delta \tilde{\nu}=\Delta A /(\mathrm{d} A / \mathrm{d} \tilde{\nu})$ was $\sim 39 \mathrm{~cm}^{-1}$ which is close to the shift of J-band $\left(\Delta \tilde{\nu}_{J} \approx 36 \mathrm{~cm}^{-1}\right)$ measured at the same pump intensity. The dressedatom theory predicts a blue shift $2 \Omega^{2} /\left(\omega_{0}-\omega_{\mathrm{p}}\right)$ of transition frequency for two-level system, where $\Omega^{2}$ is the square of Rabi frequency, the latter being proportional to pump intensity, $\omega_{0}$ is a transition frequency between two atomic levels, and $\omega_{\mathrm{p}}$ is pump frequency. The same prediction for the value of optical Stark shift was showed to be valid for excitons at large below-gap detuning in semiconductors by Combescot et al [11]. The simplification of the model at large detuning is possible by neglecting the Coulomb interactions whose energy is much less than the detuning. Hamiltonian for 
J-aggregates can be obtained within Heitler-London approximation [12]:

$$
\widehat{H}_{e}=\sum_{n} \hbar \omega_{n} \hat{b}_{n}^{\dagger} \hat{b}_{n}+\sum_{n \neq m} J_{n m}\left(\hat{b}_{n}^{\dagger} \hat{b}_{m}+\hat{b}_{m}^{\dagger} \hat{b}_{n}\right) .
$$

Here, $\hat{b}_{n}$ and $\hat{b}_{n}^{\dagger}$ denote the Pauli annihilation and creation operators for an excitation on molecule $n, \hbar \omega_{n}$ is the electronic excitation energy of the $n$th molecule, and $J_{n m}$ is the dipole-dipole interaction energy between nearest-neighbour molecules:

$$
J_{n m}=\frac{\boldsymbol{\mu}_{n} \cdot \boldsymbol{\mu}_{m}-3\left(\boldsymbol{r}_{m n}^{0} \cdot \boldsymbol{\mu}_{n}\right)\left(\boldsymbol{r}_{n m}^{0} \cdot \boldsymbol{\mu}_{m}\right)}{4 \pi \varepsilon_{0}\left|\boldsymbol{r}_{m n}\right|^{3}},
$$

where $\boldsymbol{r}_{m n}^{0}=\boldsymbol{r}_{m n} /\left|\boldsymbol{r}_{m n}\right|,\left|\boldsymbol{r}_{m n}\right|$ is the distance between the nearest-neighbour molecules, $\boldsymbol{\mu}_{n}$ is the dipole moment of the $n$th molecule.

In analogy with Combescot et al [11] where Coulomb interactions were neglected (free-electron limit) for large detuning of irradiation photon energy, the nearest-neighbour interaction energy $J_{n m}$ could be neglected in this case, because the pump detuning $\left(\sim 8000 \mathrm{~cm}^{-1}\right)$ was suitably larger than nearest-neighbour interaction energy $J=\sim 790 \mathrm{~cm}^{-1}$. As a result, we observed the OSE induced blue shift of the J-band of almost the same magnitude as for dye monomers, though dipole moment of J-aggregates was a few times bigger than that of monomers [12]. The latter means that no coherent exciton size enhancement of far offresonance OSE in aggregates is observed. Similarly, no exciton size enhancement was found for nonlinear third order optical susceptibility far off-resonance. For far off-resonance case, the nonlinear third rank susceptibility was predicted to be linearly dependent on aggregates size $[1,2]$, what implies the same nonlinear optical response of $N$ monomers as of aggregate composed of $N$ coherently coupled molecules.

Another common feature of the difference spectra is the bleaching which is expressed as decrease in absorption at the peak of the shifted band as well as decrease of the area under the J-band shape. Finally, change in the shape of the band is noticeable. It is most evident from the fact that the high-energy side of J-band shifts less than the low-energy one (Fig. 2). Different OSE responses of oriented J-aggregates to the polarized pump seem to offer the key for qualitative explanation of the results obtained. In the case of parallel pump the macroaggregates are mainly affected by OSE, the spectral signature of which is the blue shift of the "blue" fraction or macroaggregates of the J-band (see Fig. 2, middle). The characteristic changes in optical density in the latter case are higher positive val- ues in the blue wing of J-band $((\|\|)$ and $(\| \perp)$ cases, where the first symbol denotes the pump and the second the probe polarizations). The evidences of broadening of the band are observed as the positive values of normalized absorption change in the red wing of the band which can be due to overtones or combination modes of Raman as in [4] but with less contribution to differential spectra. The real excitons created by two-photon absorption result in stimulated emission well noticeable in the cases $(\| \perp)$ and $(\perp \|)$. The negative changes due to stimulated emission result in decrease of transient absorption in the red wing of the band. Lower values of induced absorption in the blue wing of J-band are the characteristic feature of the OSE of isotropically dispersed mesoaggregates $((\perp \|)$ and $(\perp \perp)$ cases). Higher bleaching and broadening of the J-band are observed for $(\perp \perp)$ case. Also, the blue shift of blue and red wings of J-band is distinctly bigger for (\| \|) case than for other cases. This can be due to considerable orientation not only of macroaggregates, but also of significant part of mesoaggregates of which the macroaggregates consist.

The J-band responds to the off-resonance pump by fully reversible blue shift, bleaching, and broadening of absorption band being due to optical Stark effect. The observed polarization dependence of OSE induced absorption changes can be qualitatively understood assuming the dual nature of the J-band as being composed of "blue" dichroic macroaggregate contribution and "red" isotropic mesoaggregate band.

\section{Conclusion}

The blue shift of aggregate transition energy, bleaching, and broadening of J-band absorption due to OSE have instantaneous character under our experimental conditions and follow the intensity variation in the pump pulse. The observed polarization dependence of the OSE induced absorption changes of oriented samples can be qualitatively understood as the dual nature of the J-band. The far off-resonance OSE in J-aggregates seems to exhibit no enhancement due to coherent exciton size.

Taking into account the instantaneous character of OSE induced changes in optical transmission, we find off-resonance optical Stark shifting of aggregate band to be fast and effective method to control optical signals in visible range by infrared light. It could find application for molecular switching devices in prospect. 


\section{References}

[1] F.C. Spano and Sh. Mukamel, Nonlinear susceptibilities of molecular aggregates: Enhancement of $\chi^{(3)}$ by size, Phys. Rev. A 40(10), 5783-5801(1989).

[2] J. Knoester, Nonlinear optical susceptibilities of disordered aggregates: A comparison of schemes to account for intermolecular interactions, Phys. Rev. A 47(3), 2083-2098 (1993).

[3] Sh. Mukamel, P. Rott, and V. Chernyak, Optical Stark spectroscopy of molecular aggregates, J. Chem. Phys. 104(14), 5415-5423 (1996).

[4] F. Sasaki, T. Kato, and S. Kobayashi, Coherent transients of virtual excitons in pseudoisocyanine $\mathrm{J}$ aggregates: Intermediate exciton-phonon interaction system, Phys. Rev. B 63(20), 205411 (2001).

[5] F. Sasaki, T. Kato, and S. Kobayashi, Phonon-mediated coherent transients in pseudoisocyanine J aggregates, J. Lumin. 87-89, 892-894 (2000).

[6] K. Misawa, H. Ono, K. Minoshima, and T. Kobayashi, New fabrication method for highly oriented J aggregates dispersed in polymer films, Appl. Phys. Lett. 63(5), 577-579 (1993).
[7] T. Kobayashi, Excitons in J-aggregates with hierarchical structure, Supramolecular Science 5(3-4), 343-347 (1998).

[8] T. Kobayashi and K. Misawa, Hierarchical structure of one-dimensional J-aggregates, J. Lumin. 72-74, 38-40 (1997).

[9] K. Misawa, Sh. Machida, K. Horie, and T. Kobayashi, Wavelength and polarization dependence of spectral hole-burning efficiency in highly oriented J-aggregates, Chem. Phys. Lett. 240(1-3), 210-215 (1995).

[10] K. Misawa, K. Minoshima, H. Ono, and T. Kobayashi, Giant static dipole moment change on electronic excitation in highly oriented J-aggregates, Chem. Phys. Lett. 220(3-5), 251-256 (1994).

[11] M. Combescot and R. Combescot, Optical Stark effect of the exciton: Biexcitonic origin of the shift, Phys. Rev. B. 40(6), 3788-3801 (1988).

[12] P.O.J. Scherer, in: J-Aggregates, ed. T. Kobayashi (World Scientific, Singapore, 1996) pp. 95-110.

\title{
OPTINIS ŠTARKO EFEKTAS ORIENTUOTUOSE PSEUDOIZOCIANINO J AGREGATUOSE
}

\author{
R. Gadonas, A. Čiburys, A. Savickas \\ Vilniaus universitetas, Vilnius, Lietuva
}

\section{Santrauka}

Darbe tiriamas optinis Štarko efektas (OŠE) stipriai orientuotuose 1,1'-dietil-2,2'-cianino chlorido (PIC-Cl) J agregatuose, ìterptuose i PVA plèvelę, esant nerezonansiniam (nederinimas $8000 \mathrm{~cm}^{-1}$ ) impulsiniam (1 ps trukmès) žadinimui. Stebimi OŠE sukelti sugerties pokyčiai yra keliu $\mathrm{cm}^{-1}$ dydžio J juostos mèlyna- sis poslinkis, juostos blyškimas ir plitimas. Eksperimento sąlygomis sugerties pokyčiai buvo momentinio pobūdžio. Stebima poliarizacinė priklausomybė kokybiškai paaiškinta nevienalyčiu J juostos pobūdžiu. Panašaus dydžio Štarko poslinkis dažų monomeriniame tirpale ir agregatuose liudija apie neeksitoninès prigimties OŠE atsaką J agregatuose didelio žadinimo nederinimo sąlygomis. 